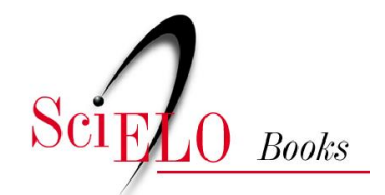

\title{
Formação e evolução histórica da estrutura agrária da região
}

\author{
Odacir Luiz Coradini
}

\section{SciELO Books / SciELO Livros / SciELO Libros}

CORADINI, OL., and FREDERICQ, A. Agricultura, cooperativas e multinacionais [online]. Rio de Janeiro: Centro Edelstein de Pesquisas Sociais, 2009. pp. 7-33. Formação e evolução histórica da estrutura agrária da região. ISBN: 978-85-7982-009-0. Available from SciELO Books $<\underline{\text { http://books.scielo.org }>\text {. }}$

\section{(1) $(0)$}

All the contents of this chapter, except where otherwise noted, is licensed under a Creative Commons Attribution-Non Commercial-ShareAlike 3.0 Unported.

Todo o conteúdo deste capítulo, exceto quando houver ressalva, é publicado sob a licença Creative Commons Atribuição Uso Não Comercial - Partilha nos Mesmos Termos 3.0 Não adaptada.

Todo el contenido de este capítulo, excepto donde se indique lo contrario, está bajo licencia de la licencia Creative Commons Reconocimento-NoComercial-CompartirIgual 3.0 Unported. 


\section{Formação e evolução histórica da estrutura agrária da região}

Procuramos a seguir delinear as bases históricas gerais em que se deu a ocupação do solo e a formação da estrutura fundiária do Sul do Brasil e as transformações pelas quais passa a estrutura agrária na medida em que a produção agrícola se incorpora de maneira mais estreita à produção capitalista em geral e agroindustrial em especial. Desse modo, num primeiro momento tentamos caracterizar a formação da estrutura agrária e fundiária em sua especificidade em relação à estrutura fundiária brasileira em geral, para, a seguir, explicitar as tendências básicas no tocante à sua evolução e às relações de produção. $\mathrm{Na}$ seção seguinte traçamos as linhas gerais do contexto macroeconômico em que se desenvolve a produção agrícola, em especial de trigo e soja, carros-chefe do tipo de agricultura e cooperativismo em questão.

\subsection{A formação da estrutura agrária do Sul do Brasil}

A formação e a consolidação da pequena propriedade rural nos três Estados do Sul do Brasil devem-se sobretudo à imigração estrangeira. $\mathrm{O}$ caráter específico da integração dos Estados do extremo sul desde o período colonial até a Revolução de 1930 fez com que a imigração para esses Estados fosse decorrente de outros fatores e tivesse resultados diferentes de outros Estados, como São Paulo. Enquanto a imigração estrangeira para São Paulo visava basicamente o suprimento de mão-de-obra para a lavoura cafeeira, que passaria a substituir a mão-de-obra escrava, para os Estados do extremo sul a finalidade básica da imigração era a ocupação efetiva do solo e sua defesa da fronteira com os países do Prata. ${ }^{3}$

A história da ocupação do solo sulino proporcionou o surgimento de suas duas faces básicas: de um lado, a grande propriedade fundiária, resultado da ocupação dos campos limpos através da concessão de sesmarias e, de outro, a pequena propriedade familiar, a partir da imigração. Se, nas demais regiões brasileiras, a pequena propriedade familiar podia constituir-se em ameaça para o latifúndio, no Rio Grande do Sul e nos Estados sulinos em geral esse problema tem características próprias. A

${ }^{3}$ Lando, Aldair M. e Barros, Eliane C., A colonização, alemã no Rio Grande do Sul. Porto Alegre, Movimento, 1976, pp.40-41. 
pecuária extensiva e a produção de charque - ou seja, a produção da grande propriedade fundiária no Sul - não requeriam o mesmo volume de mão-deobra da produção cafeeira, e a produção agrícola das "colônias" de imigrantes nada teria em comum com a produção dos grandes estabelecimentos. Enquanto as "colônias" se dedicavam à policultura, com base no trabalho familiar (a própria legislação proibia o uso do trabalho escravo nas "colônias"), as estâncias possuíam sua base econômica na pecuária extensiva e na produção de charque, ocupando os campos limpos, com base no trabalho escravo ${ }^{4}$ (e mais tarde no trabalho assalariado).

$\mathrm{O}$ exposto anteriormente e o relativo fracasso da tentativa oficial de ocupação efetiva do solo no Sul através da imigração açoriana fizeram com que existissem duas correntes de imigração para o Brasil, quanto aos objetivos, à iniciativa e ao sistema de produção. Uma, visando basicamente a instituição da pequena propriedade, teve como suporte principal a ação oficial, localizando-se no Sul; outra, tendo como objetivo básico a importação de braços para a lavoura cafeeira, com importante participação da iniciativa privada, localizou-se em sua maior parte em São Paulo. No Sul, onde o imigrante se fixava com fins de colonização, a pequena propriedade seria complementar à grande produção, enquanto ocupação do solo e fornecimento de bens alimentares e artesanais, que deixavam de ser economicamente importantes para o latifúndio.

Como mostraremos mais adiante, parte da área ocupada pela pecuária extensiva passou a ser paulatinamente ocupada pela lavoura, com as modificações introduzidas na produção agrícola, sobretudo a partir do desenvolvimento industrial, desde a década de 1950. Por sua vez, a pequena produção agrícola formada pela imigração estrangeira foi desde o início o ponto de partida para um processo de expansão permanente dessa forma de produção, através de sucessivos desdobramentos, para mais tarde ser gradativamente incorporada e subordinada ao capitalismo industrialfinanceiro.

\footnotetext{
${ }^{4}$ Lando, A.M. e Barros, E.C., op. cit., pp.21 e passim. Sobre a oposição e defesa da formação da pequena propriedade através da imigração no Brasil, ver também Dean, Waren, "Latifúndio y política en el Brasil dei siglo XIX", in Florescano, Enrique (org.), Haciendas, latifúndios y plantaciones en América Latina. México, Siglo Veintiuno, 1975.
}

Se a pequena propriedade rural no Sul do Brasil se configurou basicamente através da imigração estrangeira, numa primeira fase, seu desenrolar não se restringe à ação direta dessa corrente migratória. A corrente migratória vinda diretamente da Europa oscila e mesmo se interrompe, condicionada pelos movimentos socioeconômicos propulsores e pela política oficial do Governo brasileiro em relação à entrada de imigrantes. Todavia, inicia-se aqui uma outra corrente que já não tem origens diretamente na Europa, mas nas próprias "colônias". 5

Com as condições técnicas e sociais da produção agrícola encontradas, os imigrantes foram forçados a abandonar suas técnicas de produção a fim de se adaptarem às novas condições socioeconômicas, passando a utilizar, por exemplo, a queima e rotação de terras. Nas condições técnicas da época, consequentemente, o tamanho dos estabelecimentos apropriados pelos colonos e o crescimento demográfico das "colônias velhas", ou núcleos iniciais de imigrantes, ofereceram um excedente populacional que passou a ocupar outras áreas, em sucessivos desdobramentos. Além disso, a Lei de Terras de 1850, segundo a qual as terras devolutas não poderiam ser adquiridas por outro meio que não fosse a compra, favoreceu esse processo, ainda que os preços nem sempre favorecessem o acesso a essas terras.

Esse processo ocorreu em todas as colônias, extrapolando inicialmente as fronteiras do Rio Grande do Sul e abrangendo a fronteira agrícola do Oeste catarinense e, mais tarde, do Oeste do Paraná, Mato Grosso do Sul etc. 6 Nas "colônias novas" os excedentes populacionais surgem com maior rapidez e intensidade, em boa medida graças à

\footnotetext{
${ }^{5}$ Utilizamos aqui os termos "colônia" para designar o núcleo de colonização formado por imigrantes e/ou seus descendentes, e "colonos" para designar os imigrantes e/ou seus descendentes.

${ }^{6}$ Para uma descrição geográfica e etnográfica do processo de ampliação da área ocupada pela imigração nos três Estados do Sul, ver Weibel, Leo, Capítulos de geografia tropical e do Brasil. $2^{\mathrm{a}}$ ed., Rio, IBGE, 1979, pp.225-77. Para o desdobramento desse processo no Paraná e os conflitos resultantes, ver Westphalen, Cecília et al., "Nota prévia ao estudo da ocupação da terra no Paraná moderno", in Boletim da Universidade Federal do Paraná, (7). Curitiba, 1968, pp.2-52.
} 
diminuição do tamanho dos lotes distribuídos, ${ }^{7}$ e, numa segunda fase, graças ao processo de modernização e reorganização da produção agrícola.

Os núcleos de colonização oficial e os de iniciativa privada foram as bases para o prolongamento do processo de ocupação do solo. Contudo, mesmo quando a delimitação do tamanho da propriedade não foi fixada oficialmente, em geral não ocorreu a formação de propriedades maiores, mas ao contrário. Isso porque o processo produtivo agrícola nessas condições históricas não requeria uma área superior à recebida, nem uma expansão da área cultivada pela família, nem tampouco uma divisão social do trabalho aprofundada. Em outras palavras, a expansão da ocupação do solo baseava-se na reprodução da agricultura familiar e essa reprodução não se definia pela acumulação do capital na própria agricultura e, permanecendo a estrutura produtiva enquanto tal, esta não requeria uma divisão do trabalho que fosse além da produção familiar.

Desse modo, de um lado a expansão da pequena propriedade encontrou condições na renda diferencial, visto que as novas terras incorporadas eram terras de menor valor comercial, não pela falta de fertilidade natural, mas pelo seu estado natural e pela distância do mercado. De outro, a aquisição dessas terras era feita, geralmente, por camponeses que não tinham em vista investimentos de capital, mas a aquisição de uma área suficiente para dar conta do emprego da mão-de-obra familiar pela qual eram responsáveis, em determinadas condições técnicas e sociais. A renda diferencial possibilitaria a aquisição de uma área maior que a da região de origem, salvo as exceções, ${ }^{8}$ os camponeses que imigravam eram

${ }^{7}$ Os primeiros colonos, em 1824, recebiam cerca de 77ha. Em 1851, o tamanho dos lotes foi reduzido para cerca de 48,4ha e a partir de 1889 (colônias novas), para 25ha. Ver Roche, Jean, A colonização alemã e o Rio Grande do Sul. Porto Alegre, Globo, 1969, v. 1, p.321.

${ }^{8}$ Existe também a possibilidade da apropriação de uma área relativamente grande na região a ser colonizada. Isso poderia acontecer: 1) quando o imigrante possuía uma área relativamente grande na região de origem e transferia o valor resultante de sua venda para a região de ocupação, porque o preço da terra era quase nulo na fronteira agrícola; 2) quando o imigrante se instalava numa região de transição entre o campo e a mata, havendo a possibilidade de transformar-se em pecuarista, ou 3) quando o imigrante se transformava em comerciante, moinheiro etc. e aplicava os resultados financeiros dessas operações na compra de terras. Apesar de exceções em termos puramente numéricos, esses casos são relevantes na medida em que esse pessoal se viu favorecido, mais tarde, quando essa agricultura ingressou em outros moldes de produção e a área mínima exigida para cada unidade produtiva passou a ser maior. os que não possuíam um montante de valor maior que o necessário para a aquisição de uma área apenas suficiente para a aplicação do trabalho da família na região de destino.

O processo rápida e genericamente descrito anteriormente é relevante na medida em que é responsável pela formação da estrutura fundiária da maior parte do Rio Grande do Sul, Santa Catarina e Paraná e ainda atua como um condicionante básico nas transformações da estrutura agrária. Ainda que as condições históricas e naturais variem em determinado grau no interior da própria região, desse processo resulta que a maior parte da produção agropecuária nesses Estados provém de pequenos estabelecimentos, com base no trabalho familiar. Se tomarmos a região Sul como um todo, as exceções de monta que fogem absolutamente do padrão descrito constituem-se na zona da "campanha" ou de pecuária extensiva, cuja ocupação obedeceu a outros moldes, as regiões de produção de arroz irrigado e as regiões cafeeira e pecuária no Paraná e Santa Catarina.

A partir da ocupação do solo nessas bases, foi-se configurando nas colônias uma policultura mercantil, baseada numa variedade relativamente grande de produtos agrícolas, que oscilavam ao sabor das vicissitudes da conjuntura do mercado e das condições tecnológicas e climáticas de sua produção. Contudo, ainda que a variedade de produtos agrícolas fosse grande, na realidade essa policultura sempre esteve comandada por um ou mais produtos de maior valor comercial. Ao lado dessa agricultura mercantil, apareceram os comerciantes, ${ }^{9}$ intermediando os excedentes da produção agrícola com outros mercados e importando aqueles bens de consumo não produzidos pelo artesanato das colônias, os quais tinham um relativo peso na orientação da produção agrícola.

Todavia, a simples comercialização de uma parte da produção agrícola não significou um crescimento econômico contínuo, havendo inclusive um relativo retrocesso da agricultura em todas as colônias. Isso porque, de um lado, as condições tecnológicas dessa agricultura baseada num processo rudimentar e o tamanho dos estabelecimentos não permitiam

\footnotetext{
${ }^{9}$ Segundo Roche, já citado, os comerciantes de produtos rurais nas colônias “(...) [foram] a única classe social rural que enriqueceu" nas primeiras fases da colonização, até aparecerem as indústrias, inicialmente em sua maior parte de origens artesanais, o que vai ao encontro do corpo teórico de Susan e Dickinson, já citado.
} 
um aumento constante da produtividade ou da produção, nessas condições. A própria agricultura itinerante, além de limitada pelo tamanho dos estabelecimentos, representaria um empobrecimento progressivo do solo. Por outro lado, a realização dos excedentes comercializáveis dependia de condições mais amplas, que extrapolam as colônias, como mercado, transportes, intermediação, política governamental etc. Com efeito, até os anos 1940, em períodos de certa forma diferentes para as diversas colônias, a agricultura é marcada por uma fase de estagnação e mesmo de retrocesso tanto em relação à produtividade física quanto ao desenvolvimento tecnológico. ${ }^{10}$

A retomada do crescimento da produção agrícola aconteceu basicamente a partir da década de 1940. Os principais produtos responsáveis por essa retomada e pelo início do processo de modernização da produção, numa primeira fase, foram o trigo e o arroz, e posteriormente a produção de soja. Contudo, essa rearticulação da produção agrícola através da progressiva especialização em determinados produtos é determinada por fatores que extrapolam a região e inclusive a própria agricultura em si. Entre esses fatores podem ser enumerados o novo padrão de industrialização e urbanização do país, a política governamental e o progressivo fortalecimento e diversificação agroindustrial. A produção de soja, que surgiu em bases comerciais em especial a partir da década de 1960 e que, juntamente com a produção tritícola, contribuiu para as subsequentes transformações da estrutura agrária, insere-se de certa forma nessas

\footnotetext{
${ }^{10}$ No Rio Grande do Sul, por exemplo, onde, com exceção da rizicultura, praticamente toda a produção agrícola era feita nas colônias, tomando-se como índice 100 para a produção agrícola para 1920, o mesmo se reduz para 74 em 1924, 84 em 1928, $81 \mathrm{em} 1932$ e $87 \mathrm{em}$ 1936. A partir de 1939, tomando-se globalmente o Estado com o índice 100 para 1939, o mesmo eleva-se para 162 em 1949 e 222 em 1954, isto é, um aumento de 122\% em 15 anos. Schilling, Paulo R., A crise econômica no Rio Grande do Sul: a crise agropecuária. Porto Alegre, Difusora de Cultura e Técnica, 1961, pp.27-37. Em termos de taxa de crescimento, no período de 1920-39, a média de crescimento da agricultura gaúcha foi de 0,3 . O valor bruto da produção decresceu em média $1,6 \%$ ao ano e a área Cultivada reduziu-se numa média anual de $0,2 \%$. Já no período $1939-56$, a produção aumentou em $157 \%$, numa média anual de $5,7 \%$, o valor bruto da produção teve um crescimento médio de $6,7 \%$ e a área cultivada teve um incremento de 5,7\% ao ano. De 1956 a 1968 a produção física cresceu em cerca de $4 \%$ ao ano e o valor bruto da produção em 3\%. Incra (Coordenadoria do Rio Grande do Sul), Levantamento dos recursos naturais, socioeconômicos e institucionais do Estado. Brasília, 1972 (versão preliminar), v. 2. Sobre a crise das colônias, ver também Roche, já citado.
}

condições. Mais adiante tentaremos definir o contexto socioeconômico do desenvolvimento da produção de trigo e soja, por ser a base do cooperativismo agrícola empresarialmente mais desenvolvido no Sul do Brasil.

\subsection{A transformação da estrutura agrária}

Procuraremos nesta parte explicitar as tendências básicas provocadas pelo impacto da integração da produção agrícola na estrutura agrária e na formação de classes sociais. Deter-nos-emos em especial no caso da produção de trigo e soja no Rio Grande do Sul, visto que visaremos definir o suporte social e político do cooperativismo mais desenvolvido empresarialmente, no tocante às classes sociais na agricultura stricto sensu. Para tanto, mostraremos sinteticamente a evolução da área média das unidades produtivas para depois analisarmos as tendências básicas quanto às formas de ocupação do solo e da ocupação da força de trabalho e, consequentemente, as relações de produção resultantes desse processo.

Não obstante o considerável avanço do capitalismo e a consequente integração de boa parte da produção agrícola no Rio Grande do Sul, as alterações estruturais que esse processo provoca não podem ser consideradas quantitativamente profundas. Mesmo assim, podem-se detectar em linhas gerais, no que se refere à evolução da área média ocupada de 1940 a 1975, um aumento acelerado até 1970 e um decréscimo dos estabelecimentos considerados "pequenos" (menos de 50ha); um aumento constante dos estabelecimentos "médios" (50 a 500ha) e uma relativa estabilização da quantidade de estabelecimentos "grandes", com uma diminuição gradativa dos estabelecimentos maiores em termos de área. ${ }^{11}$

\footnotetext{
${ }^{11}$ Devido ao caráter de síntese deste texto, abstraímos as evidências empíricas mais detalhadas e restringimos a explicitação em termos conceituais àquilo que consideramos absolutamente necessário ao esboço do processo de formação das classes sociais.
} 
De qualquer modo, os dados mostram que a expansão da agricultura tida como "empresarial", nessas condições históricas, não resultou na formação de grandes estabelecimentos. ${ }^{12}$

Geralmente, a literatura corrente aborda a estrutura agrária do Rio Grande do Sul em três segmentos básicos. Esses segmentos seriam a agropecuária colonial, a pecuária tradicional e a agricultura empresarial, com origens históricas e estruturas produtivas próprias. ${ }^{13}$ Todavia, tudo leva a crer que esses segmentos, submetidos aos novos moldes decorrentes da inserção da agricultura na acumulação e reprodução do capital, na fase do capitalismo oligopólico industrial, resultam tendencialmente na configuração e progressiva consolidação de uma estrutura fundiária e produtiva, que, no limite, não condiz propriamente com nenhum dos referidos segmentos, ainda que possa conter elementos de praticamente todos eles. A pecuária tradicional perde importância tanto no tocante à área ocupada quanto à formação do valor bruto da produção, na medida em que o capital e, com ele, novas formas de produção avançam; ${ }^{14}$ a agropecuária colonial, formada em condições históricas e sociais alheias às novas formas de produção, é forçada a se readaptar, dentro de seus limites, às novas

${ }^{12}$ Cabe ponderar que, para o IBGE, uma mesma propriedade pode estar dividida em vários estabelecimentos. Contudo, os dados do Incra de 1967 a 1977 confirmam a tendência esboçada pelos dados do IBGE. Conforme estes, os imóveis com área até 50ha tiveram uma pequena diminuição, passando de $87,9 \%$ para $87,3 \%$; os imóveis com área entre 50 e 200ha aumentaram de $8,6 \%$ para $9,0 \%$ e os com mais de 200 ha, que representavam $0,15 \%$ do total em 1967 diminuíram para 0,13\% em 1977. (Dados do Incra, reorganizados por Oliveira, Péricles F.L. de, Estrutura agrária e agricultura gaúcha. Porto Alegre, CEPA, 1978, Tabela 1.2.)

${ }^{13}$ Ver, entre outros, o trabalho do Incra (Coordenadoria do Rio Grande do Sul), op. cit. e da FEE - Fundação de Economia e Estatística, 25 anos de economia gaúcha. Porto Alegre, FEE, 1975, v. 3.

${ }^{14}$ Cabe declarar que não pretendemos de forma alguma que esse avanço da lavoura tida como empresarial em relação às demais formas de produção resolva por si só a questão entre o "latifúndio" e o "minifúndio" e, por extensão, o problema da "reforma agrária", espinha dorsal da maior parte das interpretações da estrutura agrária gaúcha. Pensamos que essa questão persiste, mas a questão básica em termos socioeconômicos não se situa na resistência do "latifúndio" ao avanço da "empresa rural". A questão básica é a exclusão potencial ou efetiva da maior parte da população tanto das possibilidades de qualquer trabalho produtivo quanto das demais formas de vida social. Essa questão não se resolve com a simples substituição do "latifúndio" pela "empresa rural". Por outro lado, também a manutenção da agropecuária colonial produtivamente estagnaria a fim de evitar o êxodo rural, marginalização social etc., como querem alguns, também não resolve a questão. exigências do produto em questão e das condições macrossociais que orientam a produção agrícola.

Aparentemente, o resultado lógico dessas tendências resultaria na consolidação da grande empresa rural capitalista. Contudo, esse processo está condicionado a uma série de fatores técnicos e sociais. Assim, se, por um lado, o grupo de estabelecimentos tidos como "empresas rurais" foi o segmento que mais cresceu no Rio Grande do Sul nas últimas décadas, esses estabelecimentos em geral não podem ser considerados como empresas no sentido de grande extensão de área ocupada ou do uso de trabalho predominantemente assalariado e de certa forma, nem pela remuneração do capital investido de acordo com a taxa média de lucro, a não ser em condições e conjunturas especiais.

A condição técnica que atua no sentido de não aumentar a área dos estabelecimentos é o processo produtivo agrícola que, nessas condições, não requer o aumento da área média, ao ponto de formar grandes empresas. ${ }^{15}$ Em outras palavras, a utilização dos meios de produção em forma econômica produtiva "ótima" não necessita necessariamente de um aumento da área média ocupada pelas unidades produtivas, ${ }^{16}$ (a não ser por parte das que se situam abaixo do patamar tecnicamente necessário) e, como veremos mais adiante, nem da utilização do trabalho assalariado.

As condições sociais que atuam nesse sentido são as próprias condições que, na medida em que integram em termos produtivos a agricultura com a produção industrial e/ou capitalista, em geral a subordinam socioeconomicamente. Essa subordinação da agricultura está assentada no maior desenvolvimento, acumulação e centralização do capital em setores não agrícolas, graças basicamente à maior velocidade da rotação de capital e, portanto, à maior lucratividade nessas esferas da produção.

${ }^{15}$ Nesse aspecto, em termos teóricos, apoiamo-nos especialmente no trabalho de Servolin, C., op. cit., pp.70 e passim.

${ }^{16}$ Por exemplo, a área mínima para a aquisição de um trator, com razoável aproveitamento e viabilidade econômica, na área de influência inicial da Cotrijuí (Noroeste do Rio Grande do Sul), de acordo com os cálculos da mesma, é de cerca de 40ha. A área ótima para um bom desempenho produtivo de um estabelecimento integralmente mecanizado é de cerca de $100 \mathrm{ha}$ e, no caso de ser feita a colheita por combinada automotriz do próprio estabelecimento, a área considerada ótima é de 150ha. Já a Fecotrigo, para cálculos dos custos de produção para o estabelecimento dos preços mínimos, toma como tamanho ideal estabelecimentos com área entre 90 e 180ha. 
Essa situação, mais a atuação do Estado, contribui para que os setores nãoagrícolas atuem oligopolicamente em relação à agricultura. As próprias condições sociais poderiam contribuir para a formação da empresa capitalista no sentido conceitual do termo, como padrão de desenvolvimento da produção agrícola - evidentemente, na medida em que as condições históricas propiciassem a formação de uma burguesia rural bastante forte para exigir politicamente condições para a realização da taxa média de lucro para o capital investido na produção agrícola. ${ }^{17}$ Todavia, no tocante à produção de trigo e soja e da maior parte dos produtos agrícolas no Sul do Brasil, não é este o caso.

Desse modo, o decréscimo dos estabelecimentos de maior área e o aumento dos considerados "médios" e mesmo "pequenos" são decorrentes em boa medida da própria expansão daquilo que se tem como lavoura empresarial. Com efeito, no Rio Grande do Sul, a produção de arroz, trigo e soja é tida como a lavoura empresarial, a qual na última década passou a ser o segmento mais importante em termos produtivos. Em 1972, 92,2\% dos imóveis que produziam soja possuíam menos de $100 \mathrm{ha}$, sendo responsáveis por $70 \%$ da área colhida, enquanto apenas $0,28 \%$ dos imóveis produtores de soja possuíam mais de 500ha, representando apenas $1,24 \%$ da área colhida. Por sua vez, 94,4\% dos imóveis produtores de trigo possuíam área inferior a 100ha e esses imóveis foram responsáveis por $51,6 \%$ da área colhida. Os imóveis com mais de 500 ha que produziam trigo $-0,11 \%$ do total foram responsáveis por apenas $0,5 \%$ da produção desse cereal. ${ }^{18}$ Isso evidencia que os produtos tidos como típicos da "lavoura empresarial" são produzidos, quase exclusivamente, por estabelecimentos com área inferior à média, sendo que a maior parte da produção se dá em estabelecimentos com área inferior a 100ha, tamanho que se situa pouco acima do considerado "tamanho ótimo" do ponto de vista produtivo, para esses produtos, nessas condições.

\footnotetext{
${ }^{17}$ Ver, por exemplo, em Servolin, C., op. cit., pp.47-49, a formação do "preço político" dos

cereais na França.
${ }^{18}$ Dados das Estatísticas Cadastrais do Incra, reorganizadas por Oliveira, Péricles F.L. de, op. cit., Tabela 3.4.1. Quanto à produção de arroz, em 1979, 85\% se deveram a lavouras de menos de 100 ha e apenas $0,7 \%$ a lavouras com mais de 500 ha. Ao mesmo tempo, o tamanho médio das lavouras consideradas "grandes (acima de 9ha)" foi de 84,5ha. Ver Irga, Anuário estatístico do arroz - 1979. Porto Alegre, v. 34, p.12.
}

Esses estabelecimentos têm origem tanto nas antigas unidades produtivas coloniais, quanto em áreas anteriormente ocupadas pela pecuária tradicional. Existe porém uma relativa tendência para os estabelecimentos menores serem responsáveis por aqueles produtos menos integrados e, por isso, boa parte da produção está sendo destinada ao autoconsumo. Em certos casos, eles se dedicam a produtos com processos produtivos diversos, que ex; em outros meios de produção, área mínima menor e proporcionalmente maior inversão de força de trabalho, como ocorre com a produção de fumo, hortigranjeiros, gado leiteiro, fruticultura etc. ${ }^{19}$

De qualquer modo, na medida em que parte dessas pequenas unidades produtivas estaria abaixo das condições razoáveis do ponto de vista produtivo, a tendência seria sua eliminação, como os dados parecem apontar, em especial após 1970. No entanto, essa tendência choca-se com determinadas condições sociais, como a falta de alternativas de emprego da mão-de-obra excedente, que é agravada com o esgotamento da fronteira agrícola, aumentando assim a pressão em relação à terra. Por conseguinte, em determinados períodos e regiões esses estabelecimentos crescem em número e em área ocupada.

É importante notar que, se tomar uma área de agricultura integrada, tecnicamente desenvolvida, ${ }^{20}$ além de ter sido formada historicamente sobretudo através da pequena propriedade, as tendências antes expostas ficam mais nítidas. Isto é, apenas da relativa rigidez da estrutura fundiária em relação à crescente penetração do capitalismo na agricultura, existe uma crescente adaptação da área média dos estabelecimentos às necessidades do processo produtivo, nas condições históricas em que se dá essa produção,

${ }_{19}$ Os estabelecimentos com área inferior a 50ha no Rio Grande do Sul, em 1970, foram
responsáveis por $85,5 \%$ da produção de milho, $88,3 \%$ de feijão, $88,0 \%$ de mandioca, $91,3 \%$
de batata, 92,8\% de cana-de-açúcar, $92,2 \%$ de amendoim, $92,2 \%$ de uva, $84,2 \%$ de ovos,
$62,4 \%$ de leite, $88,4 \%$ de suínos e $86,5 \%$ da produção de aves. (Cf. IBGE, Censo
agropecuário de 1970.)
20 microrregião colonial de Ijuí, por exemplo, em 1970 já possuía a razão de um trator para
47ha. É importante notar que existe uma tendência para a mecanização e uso de insumos
modernos, que começou sendo uma prática tipicamente da grande lavoura e passou a ser
progressivamente de determinados setores e linhas de produção, independentemente do
tamanho do estabelecimento. Por exemplo, de acordo com os dados do IBGE, em 1950 os
estabelecimentos com menos de 100ha possuíam apenas $18,92 \%$ dos tratores existentes no
Rio Grande do Sul. Esse percentual passou para 40,05 em 1960 e 50,80\% em 1970 . 
através da progressiva eliminação dos estabelecimentos com área abaixo do mínimo exigido e da diminuição ou eliminação progressiva dos estabelecimentos maiores.

Quanto às formas de ocupação do solo no Rio Grande do Sul, o arrendamento está associado, de um lado, à expansão da lavoura sobre áreas anteriormente ocupadas pela pecuária extensiva - que tem na renda fundiária capitalizada seu suporte — e, de outro, à readaptação das unidades produtivas do antigo campesinato às novas formas de produção. Portanto, o arrendamento está vinculado à expansão da lavoura "especializada" e integrada ao capitalismo industrial.

A produção de trigo, soja e arroz é responsável pela maior parte dos arrendamentos. Conforme estimativas “(...) as áreas arrendadas representam aproximadamente $44 \%$ da área cultivada com trigo e soja no Rio Grande do Sul". ${ }^{21}$ No caso da produção de arroz, o arrendamento representa cerca de 60/70\% da área cultivada. As lavouras arrendadas representavam 5,60\% do número total em 1960, 7,41\% em 1970, e 5,34\% em $1975 .^{22}$

Aparentemente, esse arrendamento estaria, em geral, associado a grandes empresas capitalistas, visto que está diretamente vinculado à expansão da lavoura tida como empresarial. Contudo, o número de arrendatários evoluiu de 1920 a 1970, em 11,67 vezes, enquanto a área arrendada aumentou em apenas 1,44 vezes, o que evidencia a diminuição drástica do tamanho médio dos estabelecimentos arrendados. Com efeito, conforme dados do IBGE, a área média dos estabelecimentos arrendados, que era de 107,3 ha em 1960 , decresceu para 77,41 ha em 1975 , portanto bem abaixo do que poderia ser considerado um grande ou mesmo médio estabelecimento.

Tudo leva a crer que uma boa parte desses arrendamentos estejam vinculados à readaptação do uso do solo às novas exigências do processo produtivo, em termos de área mínima, daqueles estabelecimentos do antigo campesinato. Em outras palavras, em boa medida o arrendamento resulta da necessidade de satisfazer uma área mínima, nessas condições de produção, a qual boa parte dos antigos estabelecimentos formados a partir das colônias já não satisfazem, à medida que avança o processo de mecanização.

\footnotetext{
${ }^{21}$ Fecotrigo, Trigo/soja; custos da produção 1967,1973 e 1974. Porto Alegre, 1975.
}

${ }^{22}$ Oliveira, P.F.L. de, op. cit., p.17 e Tabela 2.1
Portanto, esse tipo de arrendamento seria mais próprio das regiões ocupadas com base na pequena propriedade e em rápida modernização do processo produtivo. ${ }^{23}$ Um exemplo típico desse processo seria a área de atuação da Cotrijuí, no Noroeste gaúcho, onde $90 \%$ de imóveis são considerados "minifúndios" e ao mesmo tempo aumenta a proporção de arrendamentos, onde praticamente não existe a grande empresa rural.

Outra forma de arrendamento é a que se processa preponderantemente nas regiões antes ocupadas pela pecuária extensiva Não se trata da readaptação da antiga "estância" e/ou latifúndios a essa forma de produção agrícola. A quase totalidade desses arrendamentos para produção agrícola é feita por agricultores com origens nas colônias. ${ }^{24}$

Nas páginas anteriores apontamos as causas pelas quais o desenvolvimento produtivo e a integração da agricultura não formam necessariamente grandes unidades produtivas no que tange à área dos estabelecimentos. No que respeita às formas de ocupação da força de trabalho, tendencialmente, também não se constitui a "empresa agrícola capitalista" a não ser em casos específicos.

À primeira vista, a não-formação de estabelecimentos de grande área poderia decorrer da intensificação do capital em uma área menor. Nesse sentido, com exceção do tamanho da área ocupada, todos os demais elementos componentes de uma empresa capitalista no sentido completo desse conceito permaneceriam inalterados, em especial a proletarização do campesinato. ${ }^{25}$ Contudo, analisando-se os dados referentes à agricultura no Rio Grande do Sul, em especial nas regiões de trigo e soja, esses dados apontam no sentido inverso. Como decorrência da especificidade do processo de produção agrícola, ou seja, suas bases técnicas em relação à aplicação de tecnologia e novos meios de produção, o aumento da

${ }^{23}$ De acordo com as Estatísticas Cadastrais do Incra, no Rio Grande do Sul, em 1972, 75,5\% dos arrendamentos para fins agrícolas eram imóveis com menos de 50ha, apenas 4,4\% dos imóveis arrendados possuíam mais de 50011a e somente 14,8\% mais de 200ha.

${ }^{24}$ A produção de arroz, por sua formação histórica e por ser cultivada com irrigação e rotação de terras e em sua maior parte em áreas anteriormente ocupadas pela pecuária é um caso que foge a esses parâmetros.

${ }^{25}$ Ver Lenin, V.I., "Nuevos datos sobre las leyes de desarrollo del capitalismo en la agricultura", in Obras escogidas. Buenos Aires, Cartago, 1973, v. 2, pp.315-32 e Graziano da Silva, J.F. (org.), Estrutura agrária e produção de subsistência na agricultura brasileira. São Paulo, Hicitec, 1978, p.72 e passim. 
produtividade física do trabalho não requer necessariamente concentração de capital e divisão social do trabalho de forma aprofundada. ${ }^{26}$ Evidentemente, trata-se do processo produtivo de produções agrícolas determinadas, isto é, produção de trigo e soja em condições tanto técnicas quanto sociais específicas. Existem produções agrícolas em outras bases, as quais requerem, portanto, outro processo de trabalho. Por outro lado, esse processo produtivo deve ser definido dentro de determinadas condições sociais e, no caso em questão, na medida em que os setores não-agrícolas, em especial a produção industrial, são o locus ou eixo principal da acumulação de capital, determinados setores da produção agrícola tornamse desatraentes enquanto acumulação de capital, ainda que dinâmicos em termos puramente produtivos.

Disso decorre que a utilização de trabalho assalariado na agricultura gaúcha é proporcionalmente mínima e inclusive, em alguns períodos e setores, tende a decrescer. ${ }^{27} \mathrm{E}$ isso acontece mesmo num contexto sócioeconômico de excesso de mão-de-obra e, por isso, mal remunerada.

De acordo com os dados do IBGE, em geral o número de trabalhadores na agricultura gaúcha cresceu em números absolutos de 1.334.039 em 1960 para 1.893.935 em 1975, o que representa um aumento de $29 \%$ nesses 15 anos. Entretanto, nesse período a única categoria de trabalhadores que aumentou proporcionalmente foi a dos "responsáveis e membros não remunerados da família", que passaram de $85,18 \%$ do total em 1960 para 89,90\% em 1975; os empregados permanentes passaram de $4,41 \%$ para $4,64 \%$; os temporários, de $8,93 \%$ para $4,43 \%$, e os parceiros, de $1,04 \%$ para $0,56 \%$ no mesmo período.

Evidentemente, ao se considerar a agricultura do Estado em seu todo incluem-se várias formas de produção, em condições diversas. Porém, essa tendência se confirma se tomar uma das áreas de agricultura mais modernizada e especializada na produção de trigo e soja, isto é, a área de influência inicial da Cotrijuí. Nessa área, a mão-de-obra familiar, que representava $80,14 \%$ em 1950 - início da produção tritícola —, passou a

\footnotetext{
${ }^{26}$ Ver Servolin, C., op. cit. pp.44-54.

${ }^{27}$ É sintomático que uma das explicações mais correntes para o não-crescimento do trabalho assalariado em alguns setores da agricultura é o Estatuto do Trabalhador Rural. Implícito a essa explicação está o pressuposto segundo o qual o trabalho assalariado nesses setores somente seria economicamente viável quando seu preço estiver abaixo do salário mínimo.
}

representar 94,18\% em 1975; enquanto isso, a mão-de-obra assalariada em conjunto em 1975 atingia apenas $4,85 \% .^{28}$ Assim, é justamente nas zonas tidas como de agricultura mais empresarial que se tende a utilizar menos mão-de-obra assalariada e mais trabalho familiar. Mesmo aquele segmento da agricultura tido como empresarial não tem no trabalho assalariado sua forma básica de ocupação do trabalho. ${ }^{29}$

Quanto às formas de ocupação de mão-de-obra especificamente na produção de soja, no Rio Grande do Sul, em 1970, existiam 252.285 trabalhadores, maiores e menores de 14 anos. Destes, 95,87\% eram responsáveis e membros não-remunerados da família, 1,05\% empregados permanentes, $2,07 \%$ empregados temporários, $0,80 \%$ parceiros e $0,18 \%$ em outra condição. Na produção de trigo, na mesma época, havia um total de 159.285 trabalhadores, $85,42 \%$ de responsáveis e membros nãoremunerados da família, 7,41\% de empregados temporários, $5,80 \%$ de empregados permanentes, $0,97 \%$ de parceiros e $0,37 \%$ em outra condição. Com efeito, tanto num como noutro caso, a mão-de-obra familiar é a base. ${ }^{30}$

Desse modo, nessa forma de expansão do capitalismo na agricultura não existe lugar para o aumento do trabalho assalariado, nem para outras formas de trabalho preexistentes como meeiros, parceiros etc. Por outro lado, esse não-crescimento e, inclusive, diminuição de um contingente considerável de assalariados não resulta da falta de mão-de-obra em potencial para se proletarizar, mas da forma de integração e subordinação da produção agrícola, a qual possibilita a transferência de valor a outros setores e a transferência dos riscos naturais à agricultura, não possibilitando a realização da taxa média de lucro a não ser em condições e setores especiais. Por exemplo, em 1975, no Rio Grande do Sul, os estabelecimentos com área até 10ha remuneravam a mão-de-obra ativa com apenas $0,34 \%$ do salário mínimo regional; os com área entre 10 e $100 \mathrm{ha}$, ${ }^{28}$ Mereceria ser discutido o sentido do uso de trabalho assalariado nessas condições.
${ }^{29}$ Em 1972 , segundo as Estatísticas Cadastrais do Incra, o latifúndio por exploração utilizava
$38,34 \%$ do total de assalariados, contra $37,50 \%$ para a empresa rural, $24,10 \%$ para o
minifúndio e $0,5 \mathrm{~J} \%$ para o latifúndio por dimensão. Nesse mesmo período, entre os
trabalhadores especificamente da empresa rural, $32,08 \%$ eram dependentes do proprietário
trabalhando e $15,90 \%$ eram assalariados permanentes.
${ }^{30}$ A produção de arroz constitui exceção, por possuir tanto uma formação histórica quanto
um processo produtivo diverso, no sentido, por exemplo, de não possuir uma mecanização integral de todas as fases do processo. 
com 0,67\%; apenas os estabelecimentos com mais de 100ha possuíam uma remuneração acima do salário mínimo regional. ${ }^{31}$

Um dos reflexos sociais mais notórios disso é o processo de migração, tanto rural/urbana quanto rural/rural para a fronteira agrícola. Em outras palavras, existe um processo violento de seleção/exclusão a partir do avanço do capitalismo na produção agrícola, impulsionado pelo aumento do preço da terra e ao 4ua1 se contrapõe a falta de alternativas de emprego da mão-de-obra excedente. ${ }^{32}$

Num esboço do que parece ser a tendência básica da formação da estrutura de classes sociais decorrente do exposto acima, o aspecto básico é a progressiva formação de uma camada de "neocamponeses", cujas unidades produtivas são altamente capitalizadas e integradas à esfera de circulação e à produção industrial e com base no trabalho familiar praticamente não utilizando outra forma de trabalho. É fundamentalmente essa camada de produtores agrícolas, juntamente com a burguesia rural, que quantitativamente é insignificante, no caso, que constitui o suporte socioeconômico e político do cooperativismo agrícola mais desenvolvido empresarialmente. Ao mesmo tempo, é sobre esse processo de violenta exclusão/marginalização/transferência de sobretrabalho e suas contradições e tensões sociais que essas organizações atuam também como catalisadoras e viabilizadoras.

Simultaneamente à afirmação dessa camada de produtores, existe a progressiva deterioração do antigo campesinato em algumas regiões e setores, a transformação do latifúndio pela lavoura mecanizada, que em alguns casos convive com outras formas de ocupação da força de trabalho, como trabalho assalariado, entre outras, quantitativamente pouco significativas.

\footnotetext{
31 Dados do Rio Grande do Sul. Programa de Investimentos Integrados para o setor agropecuário do Rio Grande do Sul. Porto Alegre, 1975. Sobre a remuneração do trabalho agrícola e os excedentes de mão-de-obra, ver ainda o trabalho do Incra. Coordenadoria do Rio Grande do Sul, op. cit., v. 2

32 “(...) o saldo migratório do Rio Grande do Sul foi sucessivamente crescente: de 97.068 no período 1940-50, passou para 162.352, no intervalo $1950-60$ e atingiu 367.330 pessoas entre 1960 e 1970.” FEE, op. cit., p.71. Ver também FEE, Indicadores sociais - RS. Porto Alegre, 4 (4), 1976.
}

\subsection{A produção de trigo e soja e a integração da produção agrícola}

Procuraremos nesta parte delinear em termos gerais a evolução da produção de trigo e soja e seus condicionantes básicos. Nesse sentido, tentaremos demonstrar que a produção de trigo e soja, carro-chefe de um processo de profundas transformações na estrutura agrária e de uma nova forma de cooperativismo, está condicionada por forças sociais e agentes que extrapolam a agricultura stricto sensu. Desse modo, embora a produção tritícola e de soja se inscreva no marco de uma nova fase de relacionamento entre a agricultura, a indústria e o capitalismo em geral, ela não apresenta apenas uma expansão quantitativa notável nas últimas décadas. Esses produtos agrícolas, num primeiro momento, e outros, mais tarde, representam a introdução e progressiva consolidação de uma nova forma de produção agrícola no Sul do Brasil, em outras bases e com outro processo produtivo, agora estreitamente integrado e subordinado à agroindústria e às políticas estatais. Portanto, se de um lado a expansão dessa forma de produção atua no sentido de provocar profundas mudanças na estrutura agrária, de outro, vincula mais estreitamente a produção agrícola ao capitalismo agroindustrial, predominantemente de capital externo, e às políticas de viabilização e reprodução do capitalismo associado-dependente.

\subsubsection{A produção de trigo}

A produção tritícola, um dos principais responsáveis pela reorganização e integração da agricultura gaúcha, foi introduzida nesse Estado, em meados do século XVIII, pelos imigrantes açorianos, visando tanto sua subsistência quanto a produção para comercialização. No começo do século XIX deu-se o auge de sua produção, mas a partir de 1820 esse cereal praticamente desapareceu do Estado. As razões básicas desse desaparecimento foram os problemas de moléstias, a expansão das charqueadas devido à crise do charque platino que atraiu os açorianos para a pecuária e à abertura dos portos em 1808, com a consequente importação de farinha norte-americana. ${ }^{33}$

\footnotetext{
${ }^{33}$ Schilling, Paulo, Trigo; o trigo e o latifúndio no Rio Grande do Sul - o acordo do trigo norte-americano - perspectiva da triticultura gaúcha. Rio, M.A./ISEB, 1959, pp.16-17.
} 
O ressurgimento da produção desse cereal deu-se com a imigração italiana e alemã, na segunda metade do século passado. Contudo, apesar dos incentivos do Governo provincial e imperial, na segunda metade do século passado e durante quase toda a primeira metade deste, o trigo manteve-se como um produto essencialmente de subsistência das colônias. ${ }^{34}$

Se a produção tritícola se manteve quase estagnada até a década de 1940, a partir de 1939 até 1956 a produção assinala resultados favoráveis, ainda que oscilantes. ${ }^{35}$ Esse crescimento decorre em boa medida dos incentivos governamentais - créditos, subsídios, garantia de preços mínimos, criação de infraestrutura de comercialização, melhorias tecnológicas. É nesse período que a produção de trigo extrapola os limites das colônias, avançando sobre áreas anteriormente ocupadas pela pecuária. ${ }^{36}$ É nesse período também que, graças aos incentivos governamentais, a mecanização da produção tritícola começa a provocar mudanças aceleradas na estrutura produtiva. Na medida em que a produção deixou de se dar exclusivamente nas colônias e avançou sobre outras áreas, transformando a antiga estrutura produtiva, a lavoura tritícola começou a se diferenciar. Não que a produção passasse a se dar exclusiva ou predominantemente em bases empresariais, mas na medida em que a triticultura passou a ser incentivada, passou a haver e a se consolidar um segmento de produtores especializados. Esse segmento, que inicialmente era constituído pelos maiores produtores, aumentou proporcionalmente ao incremento da produção e passou a ser mais tarde um fenômeno responsável por transformações paulatinas também nas colônias, na medida

\footnotetext{
${ }^{34}$ Ver Roche, Jean, op. cit. , pp.245-46.

${ }^{35}$ De 1920 a 1940, a área plantada aumentou apenas de 120.000ha para 169.517ha. Em 1958 já havia aumentado para 614.377ha, numa média anual de crescimento de aproximadamente 50.000ha no período 1940-58, ritmo só alcançado mais tarde no Rio Grande do Sul, com a produção de soja.

${ }^{36} \mathrm{O}$ interesse pela produção de trigo, principalmente na segunda metade da década de $1940 \mathrm{e}$ na segunda metade da década de 1950, atingiu também profissionais liberais, pequenos comerciantes etc., atraídos pelos incentivos governamentais. Ver Oliveira, Jorge de, Aspectos produtivos e econômicos das dez principais culturas do Rio Grande do Sul: 1948 a 1969. Porto Alegre, IEPE/UFRGS, 1971, p.64. Isso tem levado muitos a interpretarem o impulso à produção tritícola e de soja como resultado da inversão de capital de origem urbana na agricultura. Pensamos que se trata de uma confusão entre aspectos conjunturais e estruturais.
}

em que na maior parte delas o trigo - posteriormente junto com a soja passou a ser a produção hegemônica.

A partir de 1958, até 1966, as condições climáticas desfavoráveis e a mudança na política de importação de trigo - assinatura dos Acordos do Trigo com base na Public Law 480, entre 1956-57 e 1966-67 - fizeram com que com a mesma rapidez da ascensão da produção houvesse o descenso. ${ }^{37}$ Entre 1958-66 a área cultivada caiu em 39\% e entre 1958-64, em $51 \%$. Com esse declínio da produção houve uma evasão dos produtores de origem urbana e um avanço temporário da pecuária em áreas anteriormente ocupadas com produção de trigo, voltando em alguns períodos a ser as regiões coloniais os principais lugares de sua produção e onde o trigo nem sempre é o principal produto agrícola.

A partir da segunda metade da década de 1960, em especial de 1967, há uma retomada geral da produção tritícola tanto no Rio Grande do Sul quanto em termos nacionais. É a partir desse período que se consolidou a produção do trigo em outros Estados brasileiros, como é o caso do Paraná e hoje o Mato Grosso do Sul e o cerrado brasileiro. No Rio Grande do Sul, de

\footnotetext{
${ }^{37}$ Cerca de $85 \%$ do valor em cruzeiros do trigo norte-americano importado seriam emprestados ao BNDE (Banco Nacional de Desenvolvimento Econômico) e o Acordo estipulava a aprovação prévia por parte do Governo norte-americano dos financiamentos feitos pelo BNDE, ao mesmo tempo em que uma parcela fixa do total dos empréstimos seria destinada para "(...) financiamentos a empresas privadas de qualquer nacionalidade". Ver Schilling, Paulo, Trigo (...), op. cit., pp. 31-39.

É importante notar que nesse período já se delineavam algumas das bases daquilo que seria o padrão de acumulação e nele a inserção da produção agrícola, bem como da forma de produção agrícola a ser adotada. Ou seja, o tipo de agricultura representado sobretudo pelo trigo e pela soja já estava sendo articulado e gestado bem antes de 1964. De acordo com jornais do início da década de 1960, por exemplo, "750 milhões de cruzeiros vão ser destinados pela Agency for International Development dos Estados Unidos para o desenvolvimento do Sistema Brasileiro de Extensão Rural, segundo o convênio fumado no Gabinete do Ministro da Agricultura, pelos ministros Armando Monteiro Filho, embaixador Lincoln Gordon (...) e diretor da AID no Brasil, ministro Leonard Saccio.

"O acordo tem em vista o desenvolvimento de projetos para o desenvolvimento da produção agropecuária, no Brasil (...) e vai ser financiada (sic) com recursos oriundos do Acordo do Trigo, dentro dos princípios da Aliança para o Progresso. Após a assinatura do convênio, a Ascar recebeu a primeira parcela desse montante, no valor de 250 milhões de cruzeiros." (Correio do Povo, Porto Alegre, 17 de março de 1962.)
} 
1966 a 1972, a área cultivada aumentou em $392 \%,{ }^{38}$ que apesar das oscilações extremamente bruscas se manteve em ascensão.

Um dos elementos presentes no incremento ou descenso da produção brasileira de trigo é a política de importação ou produção interna, condicionada, de um lado, pelas condições climáticas brasileiras relativamente adversas e, de outro lado, por uma série de relações entre agentes socioeconômicos que envolvem a grande indústria, as indústrias produtoras de insumos, os Estados nacionais etc., cuja relação de forças muda para cada momento considerado. Em termos gerais, a evolução da política de importação ou não de trigo pode ser considerada em diversas fases, tais como o período de gestação e implementação das primeiras políticas estatais no sentido de incentivo à produção interna desse cereal e tendo a Argentina como principal fornecedor; o período do pós-guerra, até o final da década de 1960, no qual os EUA surgem como potência alimentar e se estabelecem os Acordos do Trigo e quando já começa a despontar a grande indústria de processamento (Bunge y Bom) como um dos elementos básicos na determinação da política de importação; e, finalmente, o período iniciado na segunda metade da década de 1960, de incremento à produção nacional e relativa diminuição das importações no consumo.

Para esse novo impulso à produção tritícola contribuiu uma série de condicionamentos naturais e forças socioeconômicas, as quais atuam tanto num sentido quanto noutro. Entre os condicionamentos naturais merecem destaque a baixa fertilidade natural e a acidez do solo, as condições climáticas difíceis e a escassa tecnologia, que tomam o trigo produzido no Brasil relativamente custoso. ${ }^{39}$ Entre as principais forças socioeconômicas que atuam no sentido do aumento da produção estão o próprio Estado brasileiro - entre outras coisas, tentando evitar o consumo de divisas com importações - o crescimento e consolidação do complexo agroindustrial e sua integração com a produção tritícola, o grupo de pressão política que os triticultores - agora organizados em cooperativas - representam, a

\footnotetext{
38 Ver Grzybwoski, C., "O trigo no Brasil", in Notes du GEREI (2), pp.15-42, Paris, setembro de 1977. Ver também Freitas, Luiz M. e Neto, A.D., O trigo no Brasil. São Paulo, Associação Comercial, 1960

${ }^{39}$ Ver Knight, Peter T., "Substituição de importações na agricultura brasileira: a produção de trigo no Rio Grande do Sul”, in Estudos Econômicos. São Paulo, I (3), 1971, pp.92-97.
}

complementaridade entre produção de trigo e soja, além da falta de opções para cultivos de inverno.

Por outro lado, independentemente das oscilações e da discutível racionalidade estritamente econômico-produtiva da triticultura, ${ }^{40}$ interessanos aqui a consolidação dessa produção agrícola enquanto desencadeadora de um processo de transformação da estrutura produtiva e socioeconômica e integração da agricultura em questão. Nesse sentido, o próprio desenvolvimento da produção de soja está de certo modo vinculado à produção de trigo não apenas por ser complementar, mas inclusive por ter aproveitado boa parte da infraestrutura de produção e desenvolvimento tecnológico. O mesmo está acontecendo com outros produtos com processos produtivos semelhantes.

\subsubsection{A produto de soja}

Ao lado do desenvolvimento da produção tritícola, o incremento, consolidação e, posteriormente, a hegemonia da produção de soja é um dos elementos básicos, no tocante à produção agrícola, para a explicitação das transformações da estrutura social e para $o$ fortalecimento do cooperativismo agrícola em bases empresariais. Também quanto à produção de soja não nos interessa diretamente o aumento da produtividade física em si nem o montante produzido, a não ser como indicadores das condições técnicas e sociais sob as quais se dá essa produção.

Ao mesmo tempo em que a produção de soja, em especial no Rio Grande do Sul, tem muito em comum com a produção tritícola no tocante às bases técnicas e sociais da produção, foi por seu intermédio que se deu o maior avanço no sentido da integrado da estrutura produtiva agrícola às esferas da produção capitalista em geral. Portanto, ainda que ao nível macroeconômico a posição da produção de soja seja um tanto diversa da tritícola, ao nível da estrutura produtiva complementam-se inclusive no

\footnotetext{
${ }^{40}$ As posições quanto à continuidade ou não da produção tritícola nacional ainda variam desde os que advogam a autossuficiência através de estímulos oficiais e desenvolvimento tecnológico, até sua pura e simples supressão, devido aos altos custos que sua manutenção representaria para o Estado. Cabe notar que, na medida em que já existe uma série de produtos agrícolas com alto consumo de insumos industriais, esse setor industrial não faz as mesmas pressões no sentido de seu incentivo, por haver outras opções de consumo de insumos. 
sentido de articular essa estrutura produtiva com a agroindústria e as políticas estatais.

De maneira geral, o aumento da produção brasileira de soja, em especial a partir do final da década de 1960, pode ser atribuído à conjugação de uma série de fatores, entre os quais alguns podem ser considerados como decisivos: a crescente internacionalização da economia da soja - conjugado com o fato de a soja brasileira ser colhida na entressafra dos maiores produtores mundiais; a política brasileira de incentivo à sua produção e exportação; a consolidação da indústria de processamento e da agroindústria em geral; o baixo custo da força de trabalho e da terra, comparativamente aos maiores produtores mundiais; e, no caso das regiões produtoras de trigo, a complementaridade existente ao nível da produção (insumos, tecnologia, sazonalidade), comercialização (ocupando praticamente a mesma estrutura montada para o trigo, como as cooperativas) e da política de incentivos a esses dois produtos.

De qualquer modo, o crescimento tanto da produção brasileira de soja quanto da capacidade de processamento das indústrias situadas no Brasil, em especial na última década, foi acelerado. Com efeito, no período 196675, a produção mundial cresceu em 1,60 vez e a produção brasileira em 9,28 vezes. No período de $1970-77$, o crescimento foi de $800 \%{ }^{41}$

Como a produção brasileira é destinada em sua maior parte à exportação (em grão, farelo, óleo), o Brasil ocupa o lugar de segundo exportador mundial. Essas exportações acompanham o crescimento da produção, as quais representaram 2,6\% do total das divisas das exportações brasileiras em 1970 e passaram a representar 17,6\% em 1976. ${ }^{42}$ No Rio Grande do Sul, nesse ano, a soja in natura $(33,78 \%$ ), farelo e óleo de soja em bruto representaram $62,76 \%$ do total das exportações. Por outro lado, o Brasil, que importava óleo de soja, passou a exportá-lo em 1972, ainda que esse produto tenha passado a substituir outros óleos vegetais e a banha. Cerca de 70-80\% do farelo de soja são exportados. Dependendo da safra, ainda são exportados $20-30 \%$ in natura. Os principais mercados para os

\footnotetext{
${ }^{41}$ Ver Conjuntura Econômica. Rio, 30 (11), novembro de 1976, p.119 e passim, e M.A., Comissão de Financiamento da Produção. Subsídios para fixação dos preços mínimos safra 1978-79. Brasília, 1979, p.145.

${ }^{42}$ M.A., Comissão de Financiamento da Produção, op. cit., p.145.
}

produtos com base na soja ou in natura é o Mercado Comum Europeu, países da Europa em geral, URSS e Japão.

Além da alta cotação internacional da soja, que é atribuída, basicamente, ao crescimento dos rebanhos bovinos na Europa e EUA, estimulando assim o preço do farelo, à queda da produção de farinha de peixe no Peru e à entrada da URSS na importação dessa oleaginosa, ${ }^{43}$ devese levar em conta a internacionalização do complexo de processamento e comercialização da soja. Isto é, a comercialização e, em boa medida, a industrialização da soja brasileira dependem das grandes companhias ou conglomerados internacionais que não têm necessariamente interesses estabelecidos geográfica ou nacionalmente. Com efeito, as exportações norte-americanas de soja são feitas por um número relativamente pequeno de empresas, como a Continental Grain, Cargill Incorporated, Bunge y Bom, Cargill/Tradax, Louis Dreifus, European Grain and Shopping/Andre Cie, Central Soya Co., Swift \& Co., Ralston Purina, Anderson Clayton etc., quase todas atuando também na comercialização e processamento da soja brasileira, com incentivos governamentais. ${ }^{44}$ Além disso, essas empresas geralmente atuam na forma de "Trading Companies", possuindo escritórios em todo o mundo, ao mesmo tempo em que possuem unidades de processamento nos países produtores ou consumidores, além de companhias de navegação e de seguros e incluem ramos industriais e associações com grupos financeiros.

Evidentemente, não são apenas os acidentes climáticos ou as leis de mercado atuando livremente que determinam a alta do preço internacional da soja, mas forças sociais organizadas, com interesses diversos, que abrangem desde os produtores, os grupos comerciais e industriais envolvidos no circuito produção-comercialização-transformação, até os Estados nacionais onde os EUA aparecem como força maior. ${ }^{45}$

\footnotetext{
${ }^{43}$ Conjuntura Econômica, op. cit., pp.121-22.

${ }^{44}$ Ver Rio Grande do Sul. Assembleia Legislativa. Análise do $1^{\circ}$ Simpósio Nacional da Soja. Porto Alegre, Assembleia Legislativa, 1977, p.54 e passim. Ver também Rio Grande do Sul. Assembleia Legislativa. $1^{o}$ Simpósio Nacional da Soja. Porto Alegre, Assembleia Legislativa, 1976.

${ }^{45}$ Sobre as forças sociais em jogo no "complexo soja" e a dominação norte-americana do mercado, ver Berlan, J.P. et al, "Blé et soja: pénuries sur commande?", in La Recherche, (56), Paris, maio de 1975, pp.408-17.
} 
É nesse contexto que se inserem as políticas do Estado brasileiro no sentido do aumento da produção e exportação da soja. Assim, essa oleaginosa e seus derivados (óleo, farelo) passaram a representar a maior parte do consumo e comércio internacional de oleaginosas, com uma alta taxa de crescimento. Com sua política voltada para o incremento à produção para a exportação, o Brasil ocupa o segundo lugar no comércio internacional de soja e derivados, ficando a liderança com os EUA. Entretanto, ainda que os maiores importadores de soja, como os países do Mercado Comum Europeu, dependam quase que exclusivamente de importação para suprimento de suas necessidades e não possuam condições de alcançar a autossuficiência, adotam uma política protecionista que se contrapõe à política brasileira de exportação.

Assim, “(...) cada vez que um exportador colocar um produto na Europa, terá, automaticamente, de dar uma contribuição para esse fundo (de prelevements). Por exemplo, cada vez que uma tonelada de milho do Brasil atinge a Europa (sendo que o preço de orientação é de 130 dólares) estaremos contribuindo com 20 dólares para esse fundo (...)" ${ }^{46}$

Contra isso o Estado brasileiro joga com o menor custo de força de trabalho na produção de soja, se comparada internacionalmente, o menor preço de renda fundiária e a orientação de suas políticas agrícolas seletivamente, entre as quais se incluem a racionalização e subsídios à infraestrutura de produção, comercialização, processamento e exportação de soja. No conjunto das políticas de estímulo à exportação de soja e derivados, visando uma maior competitividade internacional, destacam-se a política cambial - minidesvalorizações —, reduções do ICM e estímulos e créditos fiscais que beneficiam os agentes envolvidos no processamento e exportação dessa oleaginosa. É com base nesse conjunto de forças sociais contraditoriamente entrelaçadas que o grande capital vinculado ao processamento e comercialização internacional da soja e derivados montam suas estratégias.

Alguns autores atribuem o grande crescimento da produção e exportação brasileira de soja e sua competitividade no mercado internacional à complementaridade da produção de trigo-soja (o que não acontece nos EUA, maior produtor e exportador, responsável por mais da

\footnotetext{
${ }^{46}$ Rio Grande do Sul, Ass. Legislativa, op. cit., p.90.
}

metade da produção mundial) e à renda fundiária, que é mais baixa no Brasil em relação aos EUA, além de as empresas que operam no Brasil serem praticamente as mesmas. ${ }^{47}$ Ainda que sejam elementos básicos para a exploração, o baixo custo da força de trabalho no Brasil é determinante e tem a ver inclusive com a entrada das empresas multinacionais na comercialização e industrialização da soja no próprio país. Desse modo, em 1977, os custos para a produção de soja praticamente se equivaleriam entre os EUA e o Brasil (Rio Grande do Sul), com uma pequena margem de vantagem para a produção norte-americana, a qual contava, entre outras vantagens, com um menor preço dos insumos em geral e menores custos na comercialização (pouco mais de um décimo das despesas brasileiras). Entretanto, essas vantagens ficam praticamente anuladas na medida em que a produção norte-americana tem uma despesa com mão-de-obra 3,47 vezes superior e uma despesa com renda fundiária mais de quatro vezes superior à produção brasileira. ${ }^{48}$

\subsubsection{Outros produtos agrícolas}

Como foi dito em páginas anteriores, apesar da primeira fase da agricultura nas regiões coloniais do Sul do Brasil ter sido uma policultura, essa aparente policultura sempre esteve comandada por um ou mais produtos de maior valor comercial, os quais constituem o essencial do excedente comercializável. Logicamente esses produtos variam conforme as condições de produção e a maneira pela qual a agricultura se integra ao mercado. Paralelamente a essa produção voltada para o mercado, essa forma de agricultura se encarrega de uma série de produtos para o consumo do próprio produtor. Ao mesmo tempo, nas antigas colônias a relação entre produção para o próprio consumo e para a troca é extremamente vulnerável às oscilações conjunturais do mercado, não existindo uma delimitação 'rigorosa entre produtos para consumo e para o mercado, visto que é uma produção não especializada, não tendo uma vinculação e orientação estreita por parte das políticas oficiais e mercado ao ponto de determinar

47 Ver Berlan, Jean-Pierre et al., Le complexe soja des Etats-Unis. Paris, GEREI, 1976,pp.73-74.

48 Dados brutos extraídos de M.A., Comissão de Financiamento da Produção. Preços mínimos; regiões: Centro-Oeste, Sudeste e Sul. Safra 1977-78. Brasília, 1978, p.150. 
rigorosamente os produtos e as formas de produção, inclusive porque parte dos meios de produção é produzida através do artesanato das colônias.

$\mathrm{Na}$ medida em que essa estrutura produtiva passa a ser substituída pela produção de trigo e soja e outros produtos, em outros moldes, estes passam a ser hegemônicos em determinadas regiões. Como decorrência de uma integração mais estreita da produção agrícola à agroindústria e às políticas estatais, há uma progressiva eliminação e/ou transferência espacial dos produtos agrícolas com menor valor comercial e uma progressiva eliminação da produção para autossubsistência. Em outras palavras, a formação do "produtor especializado" e a readaptação das estruturas às novas condições da produção.

Por exemplo, em algumas regiões produtoras de trigo e soja no Sul do Brasil, a composição do valor bruto da produção chegava, em 1973, a ser composta em $80 \%$ por esses dois produtos, situação notavelmente contrastante com a maior diversidade de alguns anos antes. ${ }^{49}$ Por outro lado, em 1977, no Rio Grande do Sul, a soja e o trigo ocupavam 57\% das áreas e do valor da produção e, se acrescentarmos o arroz e o milho, a área ocupada pela lavoura aproximava-se dos $90 \%{ }^{50}$

Em relação às cooperativas, esse aspecto da especialização é relevante na medida em que o cooperativismo mais empresarialmente desenvolvido, como o vinculado à produção de trigo e soja, que surgiu no bojo do incremento a essas produções, adota uma posição abertamente contrária à monocultura. Desse modo, mesmo que alguns produtos continuem hegemônicos, a tendência é uma relativa e gradativa diversificação impulsionada de certo modo pelas cooperativas até onde essas organizações têm poder de orientação da produção, o que contribui para a diversificação das atividades das cooperativas.

Contudo, essa diversificação da produção (gado leiteiro, suinocultura, fruticultura, hortigranjeiros), seja ela promovida através das cooperativas ou da agroindústria em geral, não é um retorno à antiga policultura colonial, já que é orientada e integrada à reprodução do capital. Um fator que contribui para isso é o exagero com que a política agrícola investiu na exportação,

${ }^{49}$ Dados do Convênio Incra-Unicamp. Regiões homogêneas da agricultura (mimeog.). São Paulo, 1977, p.147.

${ }^{50}$ Dados da Lavoura Arrozeira. Porto Alegre, agosto de 1977, p.11. ampliando a necessidade de produtos de consumo interno (e mesmo para exportação, além da soja).

Do ponto de vista das cooperativas, uma das razões básicas de sua atuação nesse sentido é a necessidade de uma alternativa para as massas marginalizadas pela expansão do capitalismo na produção tritícola. Nesse sentido, pelo menos ao nível político-ideológico, o cooperativismo tentaria adaptar os pequenos estabelecimentos com área insuficiente para a produção de trigo e soja àquelas produções que exijam proporcionalmente mais trabalho e menos terra e capital. 